\title{
Incidence and risk factors of herpes zoster among hiv-positive patients in the german competence network for HIV/AIDS (KompNet): a cohort study analysis
}

Klaus Jansen ${ }^{1,2^{*}}$, Burkhard Haastert ${ }^{3}$, Claudia Michalik $^{1,4}$, Adrienne Guignard ${ }^{5}$, Stefan Esser ${ }^{1,6}$, Stephan Dupke ${ }^{1,7}$, Andreas Plettenberg ${ }^{1,8}$, Adriane Skaletz-Rorowski ${ }^{1,2}$ and Norbert H Brockmeyer ${ }^{1,2}$

\begin{abstract}
Background: HIV infection is a risk factor for the development of Herpes zoster (HZ) and its complications. Prior to antiretroviral therapy (ART), HZ incidence in HIV-infected individuals ranged from 2.9-5.1/100 person-years. There is limited evidence for the impact of ART on HZ occurrence among HIV-infected adults. We analysed the incidence of, and risk factors for, $\mathrm{HZ}$ in a large cohort of German HIV-positive patients.

Methods: The study population was taken from the German KompNet cohort, a nationwide multicenter HIV cohort study. The study population was defined by age ( $\geq 18$ years), year of first positive HIV diagnosis, CD4 values \pm 6 months from HIV diagnosis ( $\left.\mathrm{t}_{0}\right)$, and month of $\mathrm{HZ}$ diagnosis. Incidences were estimated using a Poisson distribution, and uni- and multivariate Cox proportional Hazard ratio (HR) regression models were fitted to identify risk factors for developing an initial HZ episode. Independent variables were sex, age at HIV diagnosis, route of HIV transmission, ART status, CD4 count before $\mathrm{HZ}$ episode, immunosuppressive medication, and mode of data documentation (retrospective or prospective).

Results: $\mathrm{HZ}$ incidence in the overall study population was 1.2/100 person-years. In a subset of patients for that we were able to examine risk factors the following was observed: We examined 3,757 individuals whose mean age at $t_{0}$ was 38 years. Of those individuals, 96\% were diagnosed with HIV in 1996 or later, with a mean observation time of 5.8 years. $\mathrm{HZ}$ episodes $(n=362)$ were recorded in 326 patients $(8.7 \%)$, resulting in annual $\mathrm{HZ}$ incidences of $1.7 / 100$ person-years overall, and 1.6/100 person-years for initial $\mathrm{HZ}$ cases. The main risk factors associated with an initial $\mathrm{HZ}$ episode were: not partaking in ART compared with an ART regimen containing a non-nucleoside reverse-transcriptase inhibitor (HR 0.530, $p<0.001$ ) or a protease inhibitor (HR 0.624, $p=0.004$ ); and lower CD4 count by 100 cells/ $/ \mathrm{l}$ (HR 0.918, $p=0.001$ ).
\end{abstract}

Conclusions: $\mathrm{HZ}$ incidence was 4-11-fold higher than in non HIV-infected individuals, but in our study $\mathrm{HZ}$ incidences were lower than in previous studies relating to HIV-positive patients. We showed that ART is an important protective factor for $\mathrm{HZ}$ episodes.

Keywords: Herpes zoster, HIV, Highly active antiretroviral therapy, Risk factor analysis

\footnotetext{
* Correspondence: klaus.jansen@klinikum-bochum.de

${ }^{1}$ Competence Network for HIV/AIDS, Ruhr-University, Gudrunstrasse 56,

44791 Bochum, Germany

2Department of Dermatology, Venerology, and Allergology, St. Josef-Hospital,

Ruhr-Universität Bochum, Gudrunstrasse 56, 44791 Bochum, Germany

Full list of author information is available at the end of the article
} 


\section{Background}

Herpes zoster (HZ) is the clinical manifestation resulting from the reactivation of the varicella zoster virus (VZV), and can be a debilitating illness. The incidence of $\mathrm{HZ}$ in the general population is around $0.15-0.33 / 100$ personyears [1-4], with a higher incidence $(0.5-0.9 / 100$ personyears) in individuals aged 50-80 years [5]. Incidence increases with age, along with certain conditions that impair cell-mediated immunity. HZ can be severe, resulting in hospitalisation; in some cases serious complications can occur. Human immunodeficiency virus (HIV) infection is a risk factor for the development of $\mathrm{HZ}$ and its complications [6]. In cohort studies conducted before the introduction of highly active anti-retroviral therapy (ART), the annual incidence of $\mathrm{HZ}$ in HIV-infected people ranged from 2.9-5.1/100 person-years [7-11]. The overall ageadjusted risk of $\mathrm{HZ}$ is at least 15-fold higher in homosexual men infected with HIV than in uninfected men without HIV [9]. The advent of ART has seen mortality in HIV-infected patients dramatically decline, and has reduced the incidence of the most common opportunistic infections. However, ART appears to have little effect on the incidence of $\mathrm{HZ}[12,13]$ in most groups other than children [14-19]. Results from a recent study suggested a general protective effect of modern ART regimens [20]. There is limited evidence for the impact of ART on the occurrence of $\mathrm{HZ}$ among HIV-infected adults. In this study, we analysed the incidence of, and risk factors for, HZ among HIV-infected patients within the German Competence Network for HIV/AIDS (KompNet). KompNet is an open, retrospective and prospective, multicentre disease-specific and nationwide cohort study funded by the German Federal Ministry of Education and Research [21,22].

\section{Methods}

\section{Study population and data collection}

The study population was selected from HIV-infected patients within the KompNet cohort. The cohort study was approved by the relevant ethical committees for all participating centres and was compliant with the Helsinki declaration. Between June 2004 and September 2007, the KompNet cohort comprised 44 documenting sites (21 outpatient clinics and 23 private practitioners) and included 15,381 subjects with HIV/AIDS. In September 2007, it was reduced to 25 documenting sites (10 outpatient clinics, 15 private practitioners) and 8,162 subjects. Most patients were recruited between autumn 2005 and autumn 2006. Cohort participants had approximately two visits annually. During these visits multiple clinical, laboratory, and sociodemographic variables were collected prospectively [21]. The interval length between visits ranged 4-8 months; serum samples were collected at all visits, however, cells were collected for storage at enrolment and
3 years after enrolment. Data was collected prospectively (i.e. at enrollment into the cohort), in addition chart reviews were performed and data was collected retrospectively when available on patients who attend the KompNet clinical sites before enrolment. The starting point for retrospective data collection was the time of HIV diagnosis (referred to as $t_{0}$ ).

The following inclusion and exclusion criteria were applied to define the overall study population. Inclusion criteria for subjects required them to be HIV-positive subjects enrolled in the KompNet cohort, over 18-years-old, and provided informed consent for collection and analyses of clinical and socio-demographic data and blood samples. Exclusion criteria were (Figure 1): missing date of enrolment in the cohort; missing year of first plausible positive HIV diagnosis; an interval less than 6-months between the first and last visit during the study period; ART for more than one year before HIV diagnosis; duplicate subjects; documentation of "state after HZ" but HZ never previously documented; HZ more than 1 month before a first positive HIV diagnosis. If the month of diagnosis was not documented, January was considered the month of diagnosis. Additional exclusion criteria were applied to define a subpopulation for the analysis of partly time-dependent risk factors associated with HZ (Cox-subpopulation): no documented CD4 count within a 6-month period before or after $t_{0}$; first documentation for either CD4 count or viral load more than 6 months after $\mathrm{t}_{0}$; and month of initial HZ diagnosis not available.

\section{Study period}

The analyses described in this report contain data collected from 1 January 1985 until 1 July 2010.

\section{Identification of $\mathrm{HZ}$ cases}

In the cohort database, the incidence of $\mathrm{HZ}$ cases were coded as monosegmental, multisegmental, multisegmental recurring $\mathrm{HZ}$, or a current $\mathrm{HZ}$ episode without other specifications. Cases of $\mathrm{HZ}$ were mostly diagnosed on clinical grounds. Additional available documentation of a "condition after Herpes zoster" was used only for validating initial episodes of HZ. For all patients diagnosed with $\mathrm{HZ}$ we checked if there was a prior documented diagnosis of "condition after Herpes zoster" or a prior diagnosis of $\mathrm{HZ}$ without a documented month. If either were true, patients were excluded from all analyses on initial $\mathrm{HZ}$ cases.

$\mathrm{HZ}$ cases associated with Immune Reconstitution Inflammatory Syndrome (IRIS) following the initiation of ART were investigated. $\mathrm{HZ}$ cases were considered to be associated with IRIS if $\mathrm{HZ}$ was diagnosed within 3 months following commencement of ART in ART-naïve patients. If ART-naïvety could not be ascertained, a corresponding variable was imputed as missing value. 


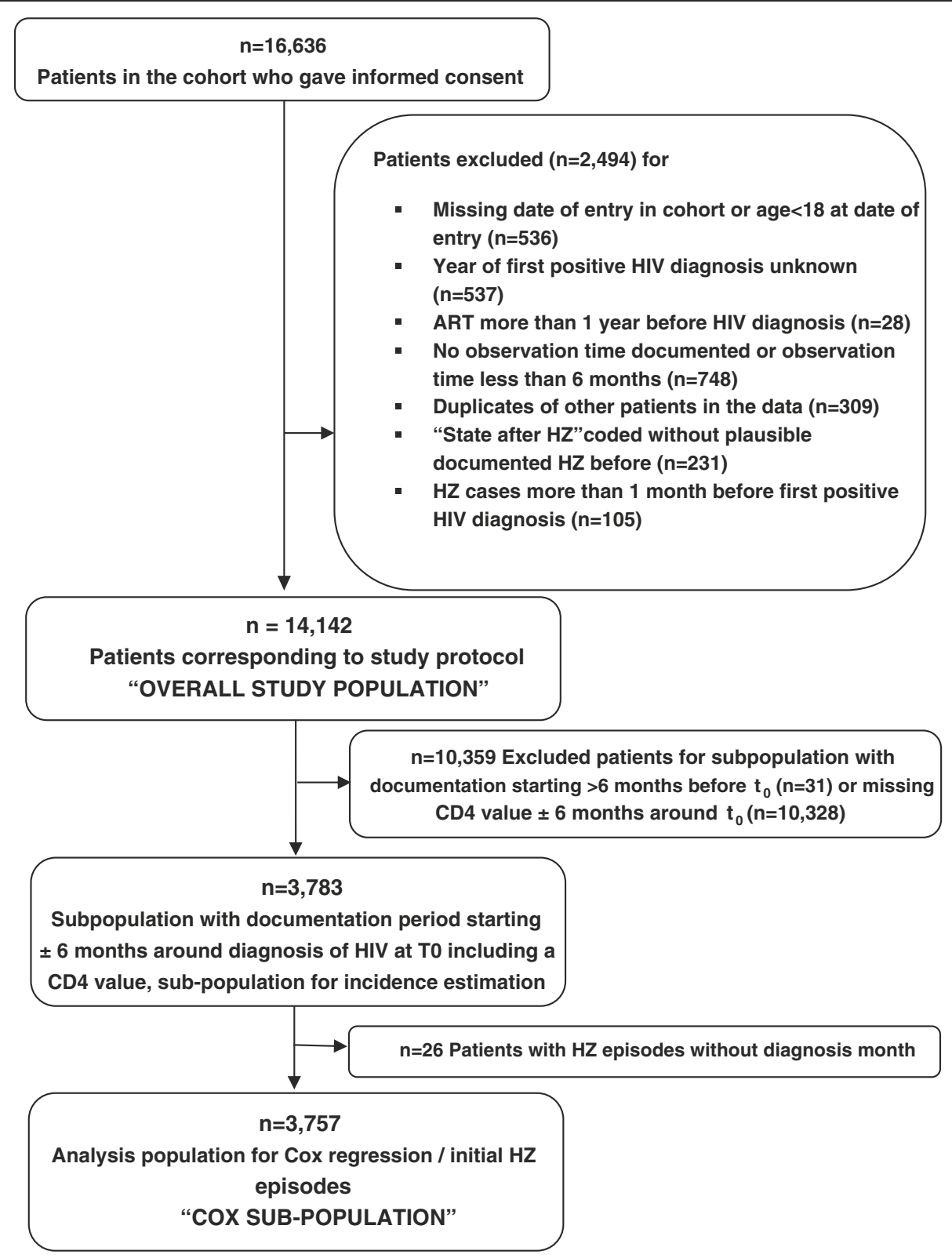

Figure 1 Selection of patients for overall study population and Cox subpopulation.

\section{Data analyses}

Baseline characteristics were described by frequencies and percentages or by means, standard deviations and ranges, depending on their distributions. Baseline characteristics were compared between the Cox subpopulation and all other patients of the total study population using the $\mathrm{X}^{2}$ - and t-tests. The incidence of $\mathrm{HZ}$ was calculated for the whole cohort at risk during the study period, based on both historical and prospectively collected data. Single and multiple diagnoses per patients were considered, with incidences of all $\mathrm{HZ}$ cases estimated as events by person-years under risk from HIV diagnosis to last date of follow-up or death. Incidences and $95 \%$ confidence intervals (CIs) were estimated assuming a Poisson distribution. HZ incidences in the Cox subpopulation, and the overall study population, were compared by fitting a Poisson regression model with a group indicator as the independent variable. Incidences were stratified by age (10-year age groups calculated by calendar year). Cumulative probabilities of initial HZ episodes depending on time since HIV diagnosis were estimated by the Kaplan-Meier method for the Cox-subpopulation.

To determine specific risk factors for time dependent analyses with respect to an initial $\mathrm{HZ}$ episode from the time of HIV diagnosis, Cox proportional hazard regression 
models were fitted [23]. For subjects without any record of a HZ episode, the last observation was taken as censored time of the patient (including death). To avoid bias for the few patients with extremely long observation times, the time under risk was truncated at a fixed maximum value (17.5 years) where at least 10 patients of the cohort were still at risk. Independent variables included baseline characteristics (sex, age at HIV diagnosis, probable route of infection) and time-dependent variables (ART status, CD4 count before the HZ episode, CD4 nadir, adjuvant medications, and mode of documentation).

CD4 values between two follow-up visits, ART status and immunosuppressive medication were assigned using the last observation carried forward (LOCF) principle. All independent variables (continuous or categorised) were first assessed in univariate models. Significant risk factors $(p<0.05)$, or those considered medically important, were then combined in a multivariate model. Some unreasonable variable combinations were excluded from multivariate models; time on ART, and different ART regimen types were not combined in one model, as periods on different ART regimen would then need to be separated. Additional bivariate models were fitted to adjust for univariate models with retrospective documentation. Gender and age were included as possible confounders in the final model to calculate age- and sexadjusted results. Results were considered statistically significant when $p$-values were less than 0.05 , and all test and confidence intervals were calculated as two-sided unless stated otherwise. Statistical analyses were performed using the statistical software package SAS 9.3 (SAS Institute Inc. Cary, NC, USA).

\section{Results}

The overall study population comprised 14,142 patients (Figure 1), with $84.9 \%$ of participants male. The Cox sub-population comprised 3,757 subjects for which all respective inclusion criteria were fulfilled. Table 1 summarises the baseline characteristics, showing that these significantly differed between both populations. Effect sizes were small for age, gender, and for the proportion of men who had sex with men (MSM). Subjects were predominantly of Western European origin and of Caucasian ethnicity (91.6\%), and nearly two-thirds were MSM. For the overall population, the mean age at HIV diagnosis was 35.1 years, with around two-thirds of all patients diagnosed with HIV diagnosed in 1996 or later. This proportion was higher (96.0\%) in the Cox subpopulation. For the overall population, the mean observation time between HIV diagnosis and last documented clinical data was 10.1 years, and the mean duration between HIV diagnosis and inclusion into the cohort was 7.5 years. For the Cox sub-population, the mean observation time was 5.8 years while the mean duration from diagnosis to inclusion in the cohort was 2.8 years. At HIV diagnosis, infectious diseases (excluding $\mathrm{HZ}$ ) accounted for the highest estimated prevalence of comorbidities (12.0\% in the overall population, $23.2 \%$ in the Cox subpopulation). Use of immune suppressive medication at HIV diagnosis was infrequent, with an estimated prevalence of $0.35 \%$ ( $0.99 \%$ in the subpopulation).

In all, 1,744 $\mathrm{HZ}$ episodes were recorded in 1,553 patients $(11.0 \%)$ in the overall study population. In the Cox sub-population, $362 \mathrm{HZ}$ episodes were recorded in 326 patients $(8.7 \%)$. Some $22 \%$ of the $\mathrm{HZ}$ cases in the overall study population (and 18\% in the Cox subpopulation) had an AIDS-defining event prior to $\mathrm{HZ}$ diagnosis (Table 2 ). The CD4 count (cells $/ \mu \mathrm{L}$; mean \pm standard deviation) at $\mathrm{HZ}$ diagnosis was $441 \pm 259(n=1,148)$, while the nadir CD4 count (cells $/ \mu \mathrm{L}$; mean \pm standard deviation) before HZ diagnosis was $292 \pm 208$ ( $n=$ total population). For $\mathrm{HZ}$ cases in the overall study population, the estimated prevalence of comorbidities at the time of HZ diagnosis was much higher than in the overall study population at the time of HIV diagnosis, with infectious diseases (excluding $\mathrm{HZ}$ ) having the highest prevalence $(42.3 \%)$.

The overall incidences of HZ were 1.22, 1.67 and 1.61/ 100 person-years for the total population, all $\mathrm{HZ}$ cases of the Cox subpopulation and initial HZ cases of the

Table 1 Baseline characteristics of patients in the overall cohort population and in the Cox-subpopulation

\begin{tabular}{|c|c|c|c|}
\hline & Total population $(n=14,142)$ & Cox-subpopulation $(n=3,757)$ & p-value ${ }^{1}$ \\
\hline Mean age at HIV diagnosis $\left(\mathrm{t}_{0}\right)$ & 35.1 years (SD: 10.2) (range 0.0-77.3) & 37.8 years (SD: 10.2) (range 14.1-77.3) & $p<0.001$ \\
\hline Proportion of men & $84.9 \%$ (17 missing) & $85.9 \%$ (2 missing) & $p=0.034$ \\
\hline Proportion of MSM & $63.5 \%$ (101 missing) & $66.4 \%$ (28 missing) & $p<0.001$ \\
\hline Proportion of IV drug users & $6.6 \%$ (101 missing) & $3.0 \%$ (28 missing) & $p<0.001$ \\
\hline Mean duration between HIV diagnosis and inclusion in the cohort & 7.5 years (SD: 6.0$)$ & 2.8 years (SD 3.2) & $p<0.001$ \\
\hline Mean duration between HIV diagnosis and last clinical data & 10.1 years (SD: 6.3) & 5.8 years (SD: 3.9$)$ & $p<0.001$ \\
\hline Proportion of timepoint of HIV-diagnosis $\geq 1996$ & $67.3 \%$ & $96.0 \%$ & $p<0.001$ \\
\hline Infectious comorbidities at HIV diagnosis (excluding HZ) & $12.0 \%$ & $23.2 \%$ & $p<0.001$ \\
\hline
\end{tabular}

1) $t$ - or $x^{2}$-tests comparing Cox subpopulation $(n=3,757)$ with all other patients of the overall study population $(n=10,385)$. 
Table $2 \mathrm{HZ}$ episodes within the study populations

\begin{tabular}{|c|c|c|c|}
\hline \multirow{3}{*}{$\begin{array}{l}\text { Patients with an } \mathrm{HZ} \text { episode } \\
\text { Episodes }\end{array}$} & \multirow{3}{*}{$\begin{array}{c}\text { Total population } \\
\text { 1,553 (11.0\%) } \\
\text { Total episodes }\end{array}$} & \multicolumn{2}{|c|}{ Cox-subpopulation } \\
\hline & & \multicolumn{2}{|c|}{$326(8.7 \%)$} \\
\hline & & Total episodes & Initial episodes \\
\hline Number of $\mathrm{HZ}$ episodes & 1,744 & 362 & 326 \\
\hline \multicolumn{4}{|l|}{ Patients with } \\
\hline 1 episode & $1,386(9.8 \%)$ & $296(7.9 \%)$ & Only initial \\
\hline 2 episodes & $145(1.0 \%)$ & $24(0.6 \%)$ & Episodes \\
\hline 3 episodes & $20(0.1 \%)$ & $6(0.2 \%)$ & \\
\hline 4 episodes & $2(0.01 \%)$ & - & \\
\hline AIDS-defining event prior to $\mathrm{HZ}$ episode ${ }^{1}$ & $22.1 \%$ (44 missing) & $18.2 \%$ (5 missing) & $18.4 \%$ (5 missing) \\
\hline Mean CD4-value/Ml at time of HZ-episode & 441 (SD: 259) (596 missing) & 434 (SD: 244) (22 missing) & 423 (SD: 240) (20 missing) \\
\hline 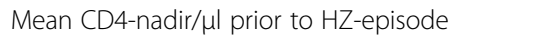 & 292 (SD: 208) (596 missing) & 275 (SD: 194) (22 missing) & 274 (SD: 193) (20 missing) \\
\hline Infectious comorbidities at time of $\mathrm{HZ}$ episode & $42.3 \%$ & $44.8 \%$ & $43.9 \%$ \\
\hline Possibly IRIS associated HZ & 4.14\% (366 missing) & $6.19 \%$ (55 missing) & 6.96\% (53 missing) \\
\hline
\end{tabular}

Cox subpopulation, respectively (Table $3, p<0.001$, Cox- vs. non-Cox subpopulations). Initial $\mathrm{HZ}$ episodes in the Cox subpopulation (Figure 2) showed a steady exponential decline up to 14 years. Overall, the 10-year probability of an HZ episode was $12.7 \%$ (95\% CI, 11.2-14.2\%). In the Cox subpopulation, $10.7 \%$ (35) of all $\mathrm{HZ}$ episodes occurred in the same month as HIV diagnosis, while $25.8 \%$ (84) of all initial $\mathrm{HZ}$ cases were observed in the first half of the year. Around 6.2\% (all HZ episodes) and 7.0\% (only initial HZ episodes) of cases in the Cox subpopulation were HZ episodes possibly linked to IRIS. Of the $84 \mathrm{HZ}$ episodes occurring within the first 6-months after HIV diagnosis in the Cox subpopulation, 13 were linked to IRIS, 34 were unable to be classified with respect to an IRIS event.

Univariate and multivariate Cox regression models were used to identify risk factors for developing an initial $\mathrm{HZ}$ episode. In the univariate model, hazard ratios for developing an initial $\mathrm{HZ}$ episode were not significant for time independent variables (sex, age, risk of transmission). Of the clinical time-dependent variables, prior exposure to ART, being on ART for $1,2,3$, or $>4$ years as opposed to no ART, having an ART-regimen containing a non-nucleoside reverse-transcriptase inhibitor (NNRTI) or a protease inhibitor (PI), or an increase in the CD4 count, significantly reduced the hazard ratio for developing an initial $\mathrm{HZ}$ episode, as did the retrospective mode of data documentation. Taking immune suppressive medication significantly increased the hazard ratio for developing an initial HZ episode (Table 4). Potential risk factors and confounders were also analysed. The main associated clinical risk factors for developing an initial $\mathrm{HZ}$ episode were: not taking an ART-regimen containing a NNRTI or a PI, and a lower CD4 count. The prospective mode of data documentation was an associated but non-clinical risk factor. Taking immune suppressive medication was no longer a risk factor after adjusting for mode of data documentation. Other significant risk factors were not influenced by adjusting the models for mode of data documentation. As in the univariate models, neither age nor sex were significant risk factors within the multivariate Cox regression

Table $3 \mathrm{HZ}$ incidence within the study populations

\begin{tabular}{|c|c|c|c|}
\hline & \multirow{2}{*}{$\begin{array}{c}\text { Total-population } \\
\text { All HZ cases }\end{array}$} & \multicolumn{2}{|c|}{ Cox-subpopulation } \\
\hline & & All HZ cases & Initial HZ cases \\
\hline Total cumulative person years & 143,174 & 21,666 & 20,271 \\
\hline Total incidence (per 100 PY) (95\% confidence intervals) & $1.22(1.16-1.28)$ & $1.67(1.50-1.85)$ & $1.61(1.44-1.79)$ \\
\hline \multicolumn{4}{|l|}{ Age stratified incidence (95\% confidence intervals) } \\
\hline $0-19$ years & $0.48(0.17-1.06)$ & $1.71(0.00-9.81)$ & $1.74(0.00-9.98)$ \\
\hline 20-29 years & $0.89(0.77-1.03)$ & $2.17(1.62-2.85)$ & $2.04(1.50-2.72)$ \\
\hline 30-39 years & $1.20(1.11-1.29)$ & $1.59(1.32-1.89)$ & $1.53(1.27-1.84)$ \\
\hline 40-49 years & $1.35(1.24-1.46)$ & $1.67(1.38-2.00)$ & $1.67(1.37-2.01)$ \\
\hline$\geq 50$ years & $1.34(1.20-1.50)$ & $1.54(1.19-1.96)$ & $1.40(1.05-1.82)$ \\
\hline
\end{tabular}




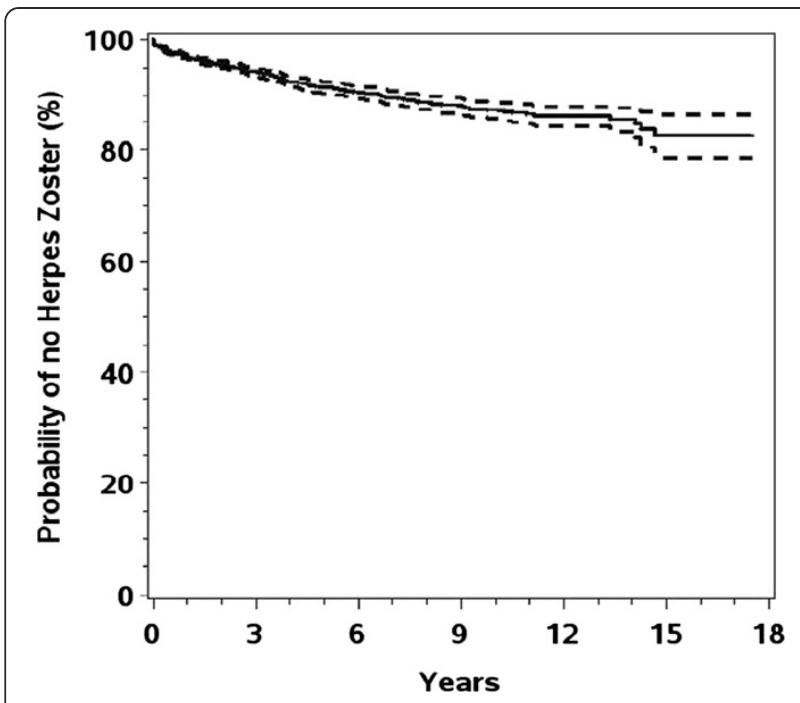

Figure 2 Kaplan-Meier curve estimating cumulative Herpes Zoster probabilities.

models. Furthermore, a sensitivity analysis after excluding all HZ cases at HIV diagnosis $(n=35)$ by fitting the multivariate model of Table 4 did not affect the results.

\section{Discussion}

In all, the KompNet cohort offers a very good opportunity to undertake epidemiological studies of HIV-positive patients in Germany because of the comprehensive nature of its data collection. For time-dependent risk factor analyses, we defined a Cox subpopulation. The reason for this was to avoid bias due to a large number of patients with incomplete documentation for long periods after $t_{0}$. A further concern was that in these periods, there was a higher probability that initial $\mathrm{HZ}$ episodes might be missed. As the first selection criterion, a documented CD4 count within a 6-month period before and after HIV diagnosis was implemented. This was used as an indicator for the beginning of a complete course of data documentation. Furthermore, subjects with a documentation interval greater than 6 months for either CD4 count or viral load data were excluded, because documented time of HIV diagnosis might no longer be valid.

The main socio-demographic and clinical characteristics of the overall study population and the Cox subpopulation were comparable, and reflected the previously reported epidemiological characteristics of HIV-positive patients in Germany with respect to age, sex, risk of transmission of HIV, origin, and dominance of MSM and geographical origin $[21,22,24]$. The statistical significance of the differences between both populations were primarily because of the large population size, however the sizes of the effects regarding these epidemiological characteristics were small.
While the use of specific populations for incidence analyses and Cox regression modelling offers a reliable methodological approach, the KompNet cohort has allowed us to study the incidence of $\mathrm{HZ}$ infection in a much larger group of patients, with the added ability of observing patients remaining free of $\mathrm{HZ}$, in contrast with previous single-centre studies [12,20].

In our study, the incidence of $\mathrm{HZ}$ was $1.2 / 100$ personyears in the overall study population and $1.7 / 100$ person-years in the Cox subpopulation. These figures are 3.6-11.3-fold higher than the $0.15-0.33 / 100$ personyears reported for the general populations of several Western countries [1-5]. Regarding HIV-positive patients, a recent analysis by Blank et al. [20] showed an incidence of 0.9/100 person-years between 2002 and 2009, which is in contrast to earlier findings at the same HIV clinic (3.2/100 person-years between 1997 and 2001) [11]. With a high proportion of patient observations in our cohort starting after 2001 (Cox subpopulation: $75 \%$ ), the results of our study are similar to the latest findings by Blank et al. [20], however we used a different study design and statistical model. It is likely that the differences between previous studies and the results of our analyses reflect a more contemporary and likely composition of current ART regimens, resulting in improved immunological conditions and thereby higher CD4 counts.

We did not observe any statistically significant differences regarding incidences stratified by age group or calendar year in either of our study populations (data not shown). The impact of older age as a risk factor for $\mathrm{HZ}$ in the general population may be abrogated in HIV-positive patients by other risk factors, such as the age-independent impairment of the immune system. The more or less stable incidence over time is in line with other findings $[12,20]$ and suggests that HZ remains an important HIVassociated infection after the introduction and on-going improvement of ART options.

As expected, the mode of data documentation had some impact on the estimation of incidences. In the Cox-subpopulation, there was a small difference between the incidence of cases documented retrospectively and those documented prospectively. Further analysis using Cox regression and another stratification indicated an underestimation of the incidence in cases documented retrospectively, which was confirmed by sensitivity analyses. This may be due to a possible recall bias for long clinical histories documented retrospectively.

Kaplan Meier-analysis showed an exponential decline and therewith a more or less constant hazard for an initial HZ episode. Overall, the 10-year probability of remaining free of an initial $\mathrm{HZ}$ episode was $87.3 \%$. We found that $10.7 \%$ of all $\mathrm{HZ}$ cases occurred at HIV diagnosis and might be the reason for HIV testing, while 
Table 4 Univariate and multivariate analysis of risk factors associated with $\mathrm{HZ}$ infection

\begin{tabular}{|c|c|c|c|c|}
\hline Variable & $\begin{array}{l}\text { Hazard ratios }(95 \% \mathrm{Cl}) \text { in } \\
\text { univariate } 1 \text { models }\end{array}$ & P-value & $\begin{array}{l}\text { Hazard ratios }(95 \% \mathrm{Cl}) \text { in } \\
\text { one multivariate model }\end{array}$ & P-value \\
\hline Male (versus female) ${ }^{2}$ & $0.952(0.703,1.290)$ & 0.752 & $0.949(0.697,1.291)$ & 0.739 \\
\hline Age (1 year change) & $1.002(0.991,1.013)$ & 0.728 & $1.002(0.991,1.013)$ & 0.758 \\
\hline MSM (versus no MSM) & $1.145(0.905,1.448)$ & 0.260 & (Not included) & \\
\hline ART naïve, time on ART: & & & (Not included) & \\
\hline ART-experienced & $0.640(0.455,0.902)$ & $0.011^{*}$ & & \\
\hline ART-naivety uncertain & $0.926(0.640,1.339)$ & 0.682 & & \\
\hline Time on ART & $0.990(0.897,1.093)$ & 0.841 & & \\
\hline \multicolumn{5}{|l|}{ (1 year change) } \\
\hline No ART (reference) & 1.000 & - & & \\
\hline ART naïve, time on ART classified: & & & (Not included) & \\
\hline ART-naivety uncertain & $0.940(0.650-1.360)$ & 0.743 & & \\
\hline ART-experienced $<1$ year & $0.901(0.631-1.287)$ & 0.567 & & \\
\hline Time on ART $1-<2$ years & $0.488(0.303-0.786)$ & $0.003^{*}$ & & \\
\hline Time on ART $2-<3$ years & $0.379(0.219-0.655)$ & $0.001^{*}$ & & \\
\hline Time on ART 3-<4 years & $0.469(0.265-0.828)$ & $0.009^{*}$ & & \\
\hline Time on ART > 4- years & $0.635(0.364-1.108)$ & 0.110 & & \\
\hline No ART (reference) & 1.000 & - & & \\
\hline \multicolumn{5}{|l|}{ ART regimen, specific } \\
\hline NNRTI-regimen & $0.557(0.396,0.783)$ & $0.001^{*}$ & $0.530(0.375,0.748)$ & $<0.001^{*}$ \\
\hline Pl-regimen & $0.703(0.512,0.965)$ & $0.029^{*}$ & $0.624(0.451,0.862)$ & $0.004^{*}$ \\
\hline Regimen with other & $0.717(0.469,1.095)$ & 0.123 & $0.729(0.469,1.131)$ & 0.158 \\
\hline \multicolumn{5}{|l|}{ Drugs/combinations } \\
\hline Treatment interruption & $1.153(0.716,1.859)$ & 0.558 & $1.108(0.686,1.789)$ & 0.675 \\
\hline No ART (reference) & 1.000 & - & 1.000 & - \\
\hline CD4-rise (of 100 cells/ $\mu \mathrm{l}$ ) & $0.939(0.898,0.983)$ & $0.006^{*}$ & $0.918(0.875,0.963)$ & $0.001^{*}$ \\
\hline Immunosuppressive medication (yes versus no) & $1.733(1.060,2.832)$ & $0.028^{*}$ & $1.510(0.921,2.477)$ & 0.103 \\
\hline Retrospective documentation (yes versus no) & $0.575(0.452,0.730)$ & $<0.001^{*}$ & $0.582(0.455,0.745)$ & $<0.001^{*}$ \\
\hline
\end{tabular}

Abbreviations: ART: anti-retroviral therapy; NNRTI: non-nucleoside reverse-transcriptase inhibitor; PI: protease inhibitor; HZ: Herpes zoster; MSM: men who have sex with men.

${ }^{1}$ For classified variables hazard ratios for each class were estimated in these "univariate" models; ${ }^{2}$ two patients with missing gender were excluded from the models including male as independent variable. No other patients were excluded from the model estimations; ${ }^{*} \mathrm{HR}$ differed significantly $(p<0.05)$ from 1 (corresponding to reference for classified variables).

$25.8 \%$ of all cases were diagnosed within the first 6 months after HIV diagnosis. Of those, a relatively high proportion (26\%) classifiable in terms of IRIS-related episodes had a HZ episode linked to IRIS.

We conducted Cox regression to identify risk factors for developing an initial HZ episode. In contrast to earlier studies [12], and in agreement with recent work [20], undertaking ART was one of the main protective factors in all our Cox regression models. A reason for this might be that the time of HIV diagnosis was defined as the starting point for estimating risk factors for a $\mathrm{HZ}$ episode, i.e. $t_{0}$. This was much earlier than in other studies, where the starting point was often defined as the first time a subject attended a clinic, being partly clinically more progressed. Another reason could be that our analyses cover a more recent era of ART, and therefore highlight the potential benefits of modern ART regimens compared with those examined in earlier studies. In addition, our study population mainly comprised MSM, who are often highly compliant with respect to medical care and treatment, especially compared with intravenous drug users.

Constant use of immunosuppressive medication was not a risk factor in our multivariate models, probably because of their infrequent occurrence in the HIV-positive patients in our study populations. Our findings corresponded with those of Blank et al. [20], where an increase in the CD4 count was a protective factor, but with a more limited impact compared with ART. Unlike other opportunistic infections, $\mathrm{HZ}$ occurs at a wide range of $\mathrm{CD} 4$ counts in 
HIV-positive subjects [18]. HZ episodes in HIV-infected patients are likely to be more severe than in non-HIV-infected subjects, and can also involve recurrent episodes, more than one dermatome, systemic manifestations, and complications such as post-herpetic neuralgia [8]. In some cases, it may be the first sign of an HIV infection; while in other individuals recurrent episodes may represent progression of HIV infection [18,25]. HIV-positive subjects who develop $\mathrm{HZ}$ infections are known to be at high risk for progression to AIDS and death [26,27]. Therefore, an improved understanding of the incidence of and risk factors for $\mathrm{HZ}$ infection in HIV-positive patients has important implications for clinical practice. Our study not only clarifies the incidence in a population which reflects that seen in contemporary practice, it also indicates a positive impact of ART and increased CD4 count to avoid initial HZ episodes in HIV-positive patients.

However, our study does have some limitations. This was an observational study, and although we adjusted for available confounders including the mode of data documentation, other biases cannot be excluded. Our results regarding risk factors can only be interpreted as associations, not as causal relations. The documentation was partially retrospective, which may have contributed to a recall bias and underestimation of $\mathrm{HZ}$ incidence. We adjusted for this as best as possible by including a corresponding time-dependent co-variable in the Cox models. Furthermore, time-dependent CD4 values used in the Cox models were imputed using the LOCF principle between neighbouring measures or until the end of observation. This might be problematic for the time course if there are longer gaps for laboratory controls in some patients. There were $35 \mathrm{HZ}$ cases at HIV diagnosis $\left(t_{0}\right)$, which may have differed from the cases during follow up. The multivariate Cox model was also fitted after excluding these 35 patients, and yielded the same result. This showed that these special HZ cases at HIV diagnosis did not bias the main results.

\section{Conclusions}

We have shown an annual HZ incidence of 1.2/100 person-years for the overall study population, and 1.7/100 person-years for the Cox subpopulation, which is 4-11fold higher than for non HIV-infected individuals. Incidences in our study were lower than those in previous studies, but in agreement with recently published analyses. For a large study population, this study showed ART as the most important protective factor for $\mathrm{HZ}$ episodes.

\section{Competing interests}

$\mathrm{KJ}, \mathrm{BH}, \mathrm{CK}, \mathrm{ASR}$, SE declare that they have no competing interests. AG is an employee of GlaxoSmithKline Biologicals. SD has received congress sponsorship, and has had consultancy and advisory relationships with Abbott, Boehringer Ingelheim, Bristol-Myers-Squibb, and Gilead. AP has received congress sponsorship, and has had consultancy and advisory relationships, and received research funding from Abbott, Boehringer
Ingelheim, Bristol-Myers-Squibb, Essex, Gilead, GlaxoSmithKline Biologicals, ViiV Healthcare, MSD Sharp \& Dohme, Pfizer, Roche, Janssen-Cilag, Sanofi Pasteur, and Novartis. NHB has received congress sponsorship, and has had consultancy and advisory relationships, while also receiving research funding from Abbott, Boehringer Ingelheim, Bristol-Myers-Squibb, Essex, Gilead, GlaxoSmithKline Biologicals, ViiV Healthcare, MSD Sharp \& Dohme, Pfizer, Roche, Janssen-Cilag, and Sanofi Pasteur.

\section{Authors' contributions}

$\mathrm{KJ}, \mathrm{BH}, \mathrm{CM}, \mathrm{AG}$ and $\mathrm{NHB}$ conceived the study and participated in its design. $\mathrm{KJ}$ and $\mathrm{BH}$ conducted the statistical analyses and drafted the manuscript. SE, $\mathrm{SD}, \mathrm{AP}$ and ASR participated in the study design and coordination. All authors read and approved the final version of this manuscript.

\section{Acknowledgements}

First, we thank all the patients participating in our cohort for providing their data and biomaterials to the cohort. We are grateful for all the work and dedication of the documentation officers and of the heads of our documenting sites. We thank the Ruhr-University Bochum for financial and structural encouragement. Especially, we thank the Federal Ministry of Education and Research for its financial support from 2002 to 2011 (grant no. BMBF-01 KI 0501). We thank Michael Holland of Driftwood Publishing Ltd for medical writing services on behalf of KompNet and Jargo Jansen of GSK Biologicals for proofreading of the manuscript.

The following documenting sites contribute data to the KompNet cohort: Gemeinschaftspraxis Driesener Straße, Berlin; Gemeinschaftspraxis Mehringdamm, Berlin; Gemeinschaftspraxis Turmstraße, Berlin; Gemeinschaftspraxis Fuggerstraße, Berlin; Praxiszentrum Kaiserdamm, Berlin; Universitätsklinikum Benjamin Franklin, Charité, Berlin; Dermatologische Klinik, Ruhr-Universität, Bochum; Universitätsklinikum Dortmund; Universitätsklinikum, Düsseldorf; Medizinische Klinik 3, Universitätsklinikum, Erlangen; Klinik für Dermatologie,

Universitätsklinikum Essen; HIVCENTER, Universitätsklinikum, Frankfurt; Ifi-Institut, Hamburg; ICH Grindelpraxis, Infektionsepidemiologisches Centrum, Hamburg; Medizinische Hochschule, Hannover; Praxis Georgstraße, Hannover;

Gemeinschaftspraxis, Kriegsstraße, Karlsruhe, Städtisches Krankenhaus Kemperhof, Koblenz; Praxis Hohenstaufenring, Köln; Gemeinschaftspraxis Isartorplatz, München; MVZ Karlsplatz, HIV Research and Clinical Centre, München; Praxisgemeinschaft Franz Joseph-Straße, München; Klinikum, Osnabrück; Gemeinschaftspraxis Ulmer/Frietsch/Müller, Stuttgart.

\section{Author details}

${ }^{1}$ Competence Network for HIV/AIDS, Ruhr-University, Gudrunstrasse 56, 44791 Bochum, Germany. ${ }^{2}$ Department of Dermatology, Venerology, and Allergology, St. Josef-Hospital, Ruhr-Universität Bochum, Gudrunstrasse 56, 44791 Bochum, Germany. ${ }^{3}$ MediStatistica, Lambertusweg 1b, 58809 Neuenrade, Germany. ${ }^{4}$ Centre for Clinical Trials, Gleueler Strasse 269, 50935 Cologne, Germany. ${ }^{5}$ GSK Biologicals, Parc de la Noire Epine, Rue Fleming, 20, 1300 Wavre, Belgium. ${ }^{6}$ Clinic of Dermatology, University Clinic,

Hufelandstrasse 55, 45147 Essen, Germany. ${ }^{7}$ Private practice Driesener Strasse, Driesener Strasse 11, 10439 Berlin, Germany. ${ }^{8}$ Ifi-Institute, Asklepios-Clinic, Lohmühlenstrasse 5, 20099 Hamburg, Germany.

Received: 11 January 2013 Accepted: 5 August 2013

Published: 10 August 2013

\section{References}

1. Kurland LT, Chu CP, Perry HO: Population-based study of herpes zoster and its sequelae. Medicine (Baltimore) 1982, 61(5):310-316.

2. Gilden DH, Kleinschmidt-DeMasters BK, LaGuardia JJ, Mahalingam R, Cohrs $\mathrm{RJ}$ : Neurologic complications of the reactivation of varicella-zoster virus. N Engl J Med 2000, 342:635-645.

3. Donahue JG, Choo PW, Manson JE, Platt R: The incidence of herpes zoster. Arch Intern Med 1995, 155:1605-1609.

4. Hope-Simpson RE: The nature of herpes zoster: a long-term study and a new hypothesis. Proc $R$ Soc Med 1965, 58:9-20.

5. Johnson R, McElhaney J, Pedalino B, Levin M: Prevention of herpes zoster and its painful and debilitating complications. Int J Infect Dis. 2007, 11(Suppl 2):S43-S48.

6. Thomas SL, Hall AJ: What does epidemiology tell us about risk factors for herpes zoster? Lancet Infect Dis 2004, 4:26-33. 
7. Buchbinder SP, Katz MH, Hessol NA, Liu JY, O'Malley PM, Underwood R, Holmberg SD: Herpes zoster and human immunodeficiency virus infection. J Infect Dis 1992, 166:1153-1156.

8. Glesby MJ, Moore RD, Chaisson RE: Clinical spectrum of herpes zoster in adults infected with human immunodeficiency virus. Clin Infect Dis 1995, 21(2):370-375.

9. Veenstra J, Krol A, van Praag RM, Frissen PH, Schellekens PT, Lange JM, Coutinho RA, van der Meer JT: Herpes zoster, immunological deterioration and disease progression in HIV-1 infection. AIDS 1995, 9:1153-1158.

10. Moore RD, Chaisson RE: Natural history of opportunistic disease in an HIV-infected urban clinical cohort. Ann Intern Med 1996, 124:633-642.

11. McNulty A, Li Y, Radtke U, Kaldor J, Rohrsheim R, Cooper DA, Donovan B: Herpes zoster and the prognosis of HIV-1 infection. Genitourin Med 1997, 73(6):467-470

12. Gebo KA, Kalyani R, Moore RD, Polydefkis MJ: The incidence of, risk factors for, and sequelae of herpes zoster among HIV patients in the highly active antiretroviral therapy era. J Acquir Immune Defic Syndr 2005, 40:169-174.

13. Vanhems P, Voisin L, Gayet-Ageron A, Trepo C, Cotte L, Peyramond D, Chidiac C, Touraine JL, Livrozet JM, Fabry J, Voirin N: The incidence of herpes zoster is less likely than other opportunistic infections to be reduced by highly active antiretroviral therapy. J Acquir Immune Defic Syndr 2005, 38:111-3.0.

14. Hung CC, Hsiao CF, Wang JL, Chen MY, Hsieh SM, Sheng WH, Chang SC Herpes zoster in HIV-1-infected patients in the era of highly active antiretroviral therapy: a prospective observational study. Int J STD AIDS 2005, 16:673-676.

15. Gona P, Van Dyke RB, Williams PL, Dankner WM, Chernoff MC, Nachman SA, Seage GR 3rd: Incidence of opportunistic and other infections in HIVinfected children in the HAART era. J Am Med Assoc 2006, 296:292-300.

16. Wood SM, Shah SS, Steenhoff AP, Rutstein RM: Primary varicella and Herpes zoster among HIV-infected children from 1989 to 2006. Pediatrics 2008, 121(1):e150-e156.

17. Levin MJ, Anderson JP, Seage GR 3rd, Williams PL, PACTG/IMPAACT $219 C$ Team: Short-term and long-term effects of highly active antiretroviral therapy on the incidence of herpes zoster in HIV-infected children. J Acquir Immune Defic Syndr 2009, 50(2):182-191.

18. Glesby MJ, Hoover DR, Tan T, Shi Q, Gao W, French AL, Maurer T, Young M, Dehovitz J, Ru J, Anastos K: Herpes zoster in women with and at risk for HIV: data from the Women's Interagency HIV Study. J Acquir Immune Defic Syndr 2004, 37:1604-1609.

19. Song JY, Lee JS, Jung HW, Choi HJ, Lee JS, Eom JS, Cheong HJ, Jung MH, Kim WJ: Herpes zoster among HIV-infected patients in the highly active antiretroviral therapy era: Korean HIV cohort study. J Acquir Immune Defic Syndr. 2010, 53:417-418.

20. Blank LJ, Polydefkis MJ, Moore RD, Gebo KA: Herpes zoster among persons living with HIV in the current antiretroviral therapy era. J Acquir Immune Defic Syndr 2012, 61(2):203-207.

21. Jansen K, Michalik C, Hahn M, Dupke S, Esser S, Jaeger H, Köppe S, Moll A, Plettenberg A, Schmidt RE, Skaletz-Rorowski A, Brockmeyer NH: Competence Network for HIV/AIDS: The patient cohort of the German Competence Network for HIV/AIDS (KompNet): A Profile. Eur J Med Res 2009, 14:323-331.

22. Jansen K, Brockmeyer NH, Hahn M, Kaul I, Fenske S, Rausch M, Kuhlmann B, Ulmer A, Lauenroth-Mai E, Harrer T, Hower M, Skaletz-Rorowski A, Michalik C: Competence Network for HIV/AIDS: Epidemiological composition, clinical and treatment characteristics of the patient cohort of the German Competence Network for HIV/AIDS. Eur J Med Res 2009, 14:415-425.

23. Kleinbaum DG, Klein M: Survival analysis: A self-learning text. 2 nd edition. New York: Springer; 2005

24. Robert Koch-Institut: Zum Welt AIDS-Tag 2010. Epidemiologisches Bulleti 2010, 46:454-459.

25. Feller $L$, Wood $\mathrm{NH}$, Lemmer J: Herpes zoster infection as an immune reconstitution inflammatory syndrome in HIV-seropositive subjects: a review. Oral Surg Oral Med Oral Pathol Oral Radiol Endod 2007, $104: 455-460$
26. Melbye M, Grossman RJ, Goedert JJ, Eyster ME, Biggar RJ: Risk of AIDS after herpes zoster. Lancet 1987, 1:728-731.

27. Alliegro MB, Dorrucci M, Pezzotti P, Rezza G, Sinicco A, Barbanera M, Castelli F, Tarantini G, Petrucci A: Herpes zoster and progression to AIDS in a cohort of individuals who seroconverted to human immunodeficiency virus. Italian HIV Seroconversion Study. Clin Infect Dis 1996, 23:990-995.

doi:10.1186/1471-2334-13-372

Cite this article as: Jansen et al:: Incidence and risk factors of herpes zoster among hiv-positive patients in the german competence network for HIV/AIDS (KompNet): a cohort study analysis. BMC Infectious Diseases 2013 13:372

\section{Submit your next manuscript to BioMed Central and take full advantage of:}

- Convenient online submission

- Thorough peer review

- No space constraints or color figure charges

- Immediate publication on acceptance

- Inclusion in PubMed, CAS, Scopus and Google Scholar

- Research which is freely available for redistribution

Submit your manuscript at www.biomedcentral.com/submit
C) Biomed Central 